\title{
Fine-tuning formative and summative assessment in Bachelors' Final Projects
}

\author{
Davinia Hernández-Leo \\ Teaching Quality and Innovation Support Unit, \\ Polytechnic School. Universitat Pompeu Fabra \\ Barcelona, Spain \\ davinia.hernandez@upf.edu
}

\author{
Verónica Moreno Oliver \\ Teaching Quality and Innovation Support Unit, \\ Polytechnic School. Universitat Pompeu Fabra \\ Barcelona, Spain \\ veronica.moreno@upf.edu
}

\begin{abstract}
The role of Bachelors' Final Projects (BFP) in Engineering Education is critical since it offers the opportunity for students to integrate the application of specific and transversal competences they have developed along the degree. However, given the special characteristics of this curriculum component (personalized according to the student's interests, multiple teachers involved, assessment by changing boards, etc.), the systematization of its formative and summative assessment has been extensively recognized as problematic but highly necessary. To face this problem, there are several recent initiatives reported in the literature that propose a set of rubrics as tools for project advisors and board members to structure the assessment. In this paper, we report the experience in the Engineering School at Universitat Pompeu Fabra (Barcelona) applying this approach based on rubrics as part of an assessment guide for BFP (Teacher's Guide to Monitoring and Assessment for BFP, designed by the support unit for teaching quality and innovation of the engineering school - USQUID-ESUP). A quantitative and qualitative evaluation of the experience provides insights about the utility, pertinence, user-friendliness, preciseness and actual use of the proposed guide. The findings indicate that several aspects of the approach applied should be revised considering the characteristics of the context of use. These aspects include the need of providing a tool for the integrated assessment of transversal and specific competences and the interest of providing a summarized version of the rubrics that can be used using mobile devices (tablets, smart phones) during board meetings. The design of this summarized version considers an aggregation of the assessment indicators associated to competences. The paper presents these findings and the designs decisions applied towards a revised version of the assessment guide for BFP.
\end{abstract}

Keywords - formative assessment, summative assessment, final projects, engineering education, tool

\section{INTRODUCTION}

As one of the critical aspects defined in the European Higher Education Area (EHEA) and its particularization to the Spanish system, the Polytechnic School of Universitat Pompeu Fabra (ESUP-UPF) has worked on the design of the formative and summative assessment used in Bachelor's Final Project (BFP). BFP is a mandatory subject for all the Bachelor's degrees (all disciplines) offered by the Spanish universities. It has specific characteristics that make it significantly different from the rest of subjects, for example: the topic of the project is different for each student and this topic is agreed between the student and a professor acting as the advisor of the student). The BFP is planned and developed by the student autonomously but with a progressive formative assessment of the teacher. It is worth noticing that the BFP at the ESUP-UPF involves a significant number of ECTS (European Credits Transfer System), namely 20 credits that represent 500 hours of student work. In their BFP students are expected to apply both specific and transversal (or generic) competences that they have developed along the degree, this includes special attention to innovation and creative skills. The high dedication to the BFP enables the elaboration of projects considerably ambitious and in most cases connected to the professional careers the students want to follow after finishing their Bachelor's Degree.

All these properties make the BFP a good opportunity to contribute to the achievement of the new missions, roles and expectations of Higher Education as pointed out by the European Commission. European universities have formulated their approaches to the BFP [1], designing a complete syllabus for that special subject [2] or a specific regulation shaping the BFP elaboration process [3]. Specific studies also analyze the learning effects of education actions designed to support the development of BFPs [4]. The Teaching Quality and Innovation Support Unit (USQUID) of ESUP-UPF has worked for the last 3 years in a Teacher's Guide to Monitoring and Assessment of BFP. The efforts have included the design of the Guide based on related international initiatives, its evaluation in pilots and the iterative revision of the Guide. In parallel a Web application implementation of the Guide has been developed to facilitate its use and foster its adoption by ESUPUPF professors. This paper summarizes this process and focused on the last iteration, which emphasizes the adaptations done to the assessment tools (assessment instrument and Web tool implementing the instrument) based on findings derived from context in which the tools are used.

The remainder of the document is organized as follows. Section II describes the methodology followed to propose, evaluate and iterate the formulation of the Guide. Section III explains the most relevant actions done in the last iteration considering the results obtained in the evaluation of the initial version of the Guide. Both sections compare the approach 
followed with related work. Section IV summarizes the main conclusions of this work.

\section{DESIGN OF THE GUIDE FOR THE ASSESSMENT OF BFPS}

\section{A. First phase: Formulation of the Guide}

In this section we present the phases considered in the whole process towards the design of the Teacher's Guide to Monitoring and Assessment for BFP. The academic implications are also discussed.

In the 2010-2011 academic course the USQUID-ESUP coordinated an internal project (UPF Program) focused on the identification of requirements for the monitoring and assessment of BFP [5]. This project built on the experiences acquired in the so-called PFCs (Proyecto Final de Carrera, in Spanish, i.e. Final Degree Project in English) in the Bachelors' Programs previous to EHEA. That means that for most Engineering Education degrees in Spain it was not new the idea that students have to complete an individual project before finalizing their degree. However, its characteristics were not the same as in BFP (e.g., less number of ECTS.). This project was complemented with a multidisciplinary workshop [6] (pedagogues and Engineering Education professors from several Catalan universities) in which ideas and approaches to the management and assessment of TFGs were shared and discussed [7-9]. Both actions were mostly reflective: brainstorming, matching the ESUP-UPF ideas with related approaches, evaluation of the relevance of existing approaches to our school, and elaboration of a Draft Guide for the monitoring and assessment of BFPs.

The results from these actions were preparatory for the second phase of the process. In the following academic course (2011-2012) the USQUID-ESUP completed a national project funded by the Spanish Ministry of Education (Estudios $y$ Análisis program) [10]. As a result of the project (with the title "Practices towards the excellence of the Bachelors Final Projects: Elaboration of a catalogue of practices based on matching the national and international frameworks and experience in the field of Engineering Education and analysis of the transfer to other contexts") diverse elements of the Draft Guide [11] was tested at the ESUP-UPF and other Engineering Schools of 6 Spanish universities. Each School adopted the elements of the guide more appropriate for their needs. The pilots involved both a selection of professors in each School and the BFP students they were supervising.

The Draft Guide and the related approaches are mostly based on rubrics, both for the formative assessment (monitoring) and for the summative assessment by a board composed of several professors in addition to the advisor [1213]. The rubrics are focused on the transversal competences. Since the topics for each BFP vary, the formulation of assessment indicators for specific competences is left open for the definition by the professors advising the particular BFPs. See a screenshot of the Web application implementing the Guide with the (incomplete) content of the rubric associated to the assessment indicator T1.1 "Quantity and Quality of Sources” (Figure 1)
Fig. 1. Screenshot of the Web application implementing the Guide, available at http://www.usquidesup.upf.edu/tfg/valoracio.en.php

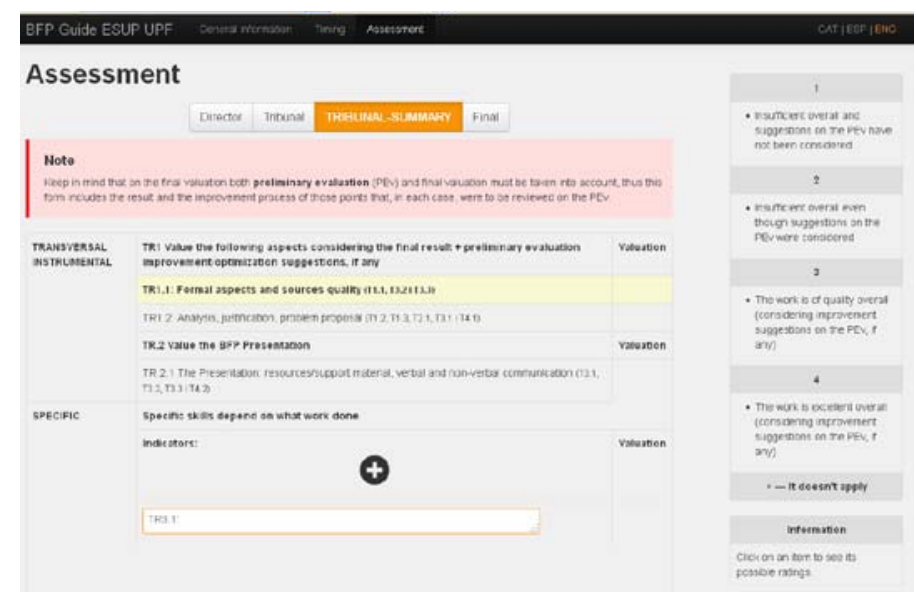

The formulation and pertinence of the indicators and the rubrics were evaluated based on the quantitative and qualitative opinion of the professors using the Guide [14]. The conclusions are discussed in next section.

\section{B. Results from the first pilots using the Guide}

The opinion of the stakeholders about the Guide was collected using a questionnaire. A total of 15 teachers (representing a 48,4\% of the professors supervising BFP) and 19 students $(67,8 \%$ of the students completing a BFP) participated in the study. The main results from the analysis of the data are:

- $92,3 \%$ of professors completing the questionnaire consider that the Guide could be an useful tool to improve the assessment process of BFP taking into account that it considers the evaluator functions (e.g. assessment criteria and competences to be evaluated).

- $100 \%$ of students completing the questionnaire consider the formative assessment as an important way to take into a count the work done during the whole process.

- $68,4 \%$ of students perceived the positive impact of knowing in advance the assessment criteria on their work (specially during the process) to, for example: balance the efforts and improve their work.

- $\quad 53,9 \%$ of professors agree/totally agree about how the Guide developed could be helpful to standardize the BFP quality and assessment criteria in both monitoring and assessment processes and $100 \%$ of them recognize the worth of the Guide to decrease the evaluator's subjectivity.

- $\quad 94,7 \%$ of students consider advisor's feedback as a quality key element during the BFP development.

- $100 \%$ of teachers consider the importance of both monitoring and assessment processes to increase the quality of BFP and $84,7 \%$ also consider the importance of establishing a continuous contact with students to assure a good work routine. 


\section{IMPLEMENTATION OF THE GUIDE}

A. Second phase: Improvement considerations for the Teacher's guide to monitoring and assessment of BFP

More meetings were done to reflect about the results [15], professors' proposals and other actions focused on testing the Guide improvements [16-17]. These actions included the revision of the Web application [18], this Web format enables:

- A more dynamic and interactive use of the Guide during the BFP defence and the discussions of the board.

- The grades are automatically calculated considering the weighting coefficient of each rubric for the indicators associated to the diverse competences.

- Professors can generate and download a PDF version of the rubrics when the assessment is done. In this way, every BFP advisor can register the students' progress, share it with the students, etc.

- Students could consult the assessment criteria and, simulate their potential grade considering a selfassessment of their progress.

\section{B. Actions done}

The Guide was revised according to the improvement considerations described and established as the official guidelines to be used at the ESUP-UPF (from pilot to implementation - 2012-2013 academic year). Training sessions were run for the professors involved in advising BFPs. The use of the Guide was not strictly mandatory for the professors (especially for those with experience supervising and assessing PFCs), but training sessions were run for those interested in their use.

At the end of defence period of the 2012-2013 academic year another study was made (based on a questionnaire). In this occasion with the objective of understanding the degree of use and opinions about utility, etc. Summary of results below.

- We collected the opinion from the $48,3 \%$ of teachers who acted as advisors and $77,8 \%$ of board members.

- All advisors affirmed that they had consulted the Guide, but not all of them used it as an assessment tool, concretely $35,7 \%$ of them affirmed that they used it during the whole process, 35,7\% affirm that they used in different parts (but not in all) and finally, 28,6\% affirm that they did not use it at all (they just looked it up while the assessment process)

- $\quad$ The same question but answered by board members indicated that $58,3 \%$ confirm its usage.

In the analysis of the explanations about why some of them used or not used the Guide, we found the following arguments: on the one hand professors emphasized the timing proposed because it includes a concrete monitoring process; the assessment criteria and the possibility to show their students how (why) and when they will be evaluated. On the other hand, teachers considered that the rubric is too long to be used during the BFP defence.

We also ask teachers and board members about the clarity, rigorous, usefulness of the Guide. 38\% of them considered the Guide especially useful for the formative assessment process, a $24 \%$ consider it especially useful for both the formative and summative assessment and, finally, a $24 \%$ consider the Guide especially useful for the final assessment.

As a final comment, the participants highlighted that the establishment of assessment criteria was easier with the Guide (67\%). Nevertheless, participants, as in the first test, perceived the need to have the chance to include explicitly the specific competences assessment and also, they suggest to "simplify" (shorten) the rubric for the defence evaluation.

\section{Evaluation of the second iteration and actions done}

As we said before, each BFP is different, so, including all specific competences in the Guide seems to be a difficult task and not that appropriate because it is not feasible to cover all the possible specific competences. To address this problem we are working on the online Guide's version to enable teachers the formulation of the specific competence by themselves. As with the transversal ones, the application will be able to calculate the final BFP qualification considering the weight assigned to these competences.

The USQUID-ESUP was also working to meet the need of having a shorter version of board's rubric. To make this shorter version we considered the number of indicators and criteria took into account in the first version to prevent an unfair treatment between boards who will use the longer rubric version and the ones who prefer the shorter. It also considers a weighting coefficient for the indicators to minimize an unfair effect depending on the rubrics used.

The following aspects were considered to match done the long and short rubrics (Table I):

- $\quad$ The longer version has 10 indicators, the shorter 3 . This matching is made considering that all indicators and criteria in are presented in both short and long version.

The shorter version includes the preliminary assessment carried out by the board. We let professors know the importance of taking into account this previous assessment to prevent an unfair treatment between both longer and shorter version (preliminary and final, see Figure 1): Keep in mind that on the final valuation both preliminary evaluation (PEv) and final valuation must be taken into account, thus this form includes the result and the improvement process of those points that, in each case, were to be reviewed on the PEV. 


\begin{tabular}{|l|l|}
\hline $\begin{array}{l}\text { TR1 Value the following aspects considering the final } \\
\text { result + preliminary evaluation } \\
\text { improvement/optimization suggestions, if any }\end{array}$ & \\
\hline $\begin{array}{l}\text { TR1.1 Formal aspects and quality of sources (T1.1, T3.2 } \\
\text { y T3.3) }\end{array}$ & \\
\hline $\begin{array}{l}\text { TR1.2 Analysis, justification, problem proposal (T1.2, } \\
\text { T1.3, T2.1, T3.1 y T4.1) }\end{array}$ & \\
\hline & \\
\hline TR2 Values the BFP defence & \\
\hline $\begin{array}{l}\text { TR2.1 The presentation: resources/ support material, } \\
\text { verbal and non verbal communication, (T3.1, T3.2, T3.3 } \\
\text { y T4.2) }\end{array}$ & \\
\hline \multicolumn{1}{|l}{ Specific skills depend on what work done: } \\
Indicators: & \\
\hline
\end{tabular}

\section{CONCLUSIONS AND FUTURE WORK}

The design of assessment instruments to be used by a teacher community is not a trivial task. Besides considering the competences to be assessed and the state of the art, it is important to understand the perception of the users about these instruments in its context of use. This paper presents a second iteration in the design of rubrics for the assessment of Bachelors' Final Projects. The main change is the design of a complementary shorter rubric that can be easily used by a committee. We are currently working on the Web implementation of the shorter rubric version shorter version of the instrument for the formative assessment. Future work includes the evaluation of the new (shorter) rubric considering both advisors and board members opinion. It is important to evaluate if this shorter version is sufficiently satisfactory.

\section{ACKNOWLEDGMENT}

The authors acknowledge the collaboration and ideas of UPF Polytechnic School professors, the members of the ESUP board and the contributions of the USQUID undergraduate technical assistants.

\section{REFERENCES}

[1] University of Twente, Bachelor Program General Information. http://www.utwente.nl/el/programme/bachelor/bachelorprogramme en/ Accessed $22^{\text {nd }}$ April 2014

[2] University College Denmark. Architectural Technology and Construction Management. Syllabus: Elective Dissertation and Bachelor Project.

http://www.viauc.com/horsens/programmes/fulldegree/constructing/Doc uments/syllabus/7-sem-final-project.pdf Accessed $22^{\text {th }}$ April 2014

[3] Technishe Universiteit Eindhoven, University of Technology. TU/e Examinations Committee's Examination Regulations, 2013-2014. http://onderwijs.ieis.tue.nl/sites/onderwijs.ieis.tue.nl/files/2009/bachelortiw/regeling/512-examination\%20regulations\%20is\%20\%202013.en.pdf Accessed $22^{\text {nd }}$ April 2014

[4] A. Miihkinen and T. Virtanen, "The Determinants of and Tools for Accounting Students' Learning in the Bachelor Thesis Seminar Course," Available at SSRN 2388648: http://ssrn.com/abstract=2388648, 2014.
[5] Project reference: Elaboration of the Guide for the Final Degree Projects of the ESUP. PlaQUID 2010-2011, Quality and Teaching Innovations Support Measures Program, CQUID, UPF.

[6] Project reference: Interuniversity Meeting to Debate and Share Experiences of Final Degree Projects. PlaQUID 2010-2011, Quality and Teaching Innovations Support Measures Program, CQUID, UPF.

[7] E. Valderrama, M. Rullan, F. Sánchez, J. Pons, C. Mans, F. Giné, L. Jiménez, and E. Peig, "Guidelines for the Final Year Project Assessment in Engineering,", 39 ${ }^{\text {th }}$ IEEE Frontiers in Education Conference, San Antonio, Texas, 2009.

[8] E. Valderrama, M. Rullan, F. Sánchez, J. Pons, C. Mans, F. Giné, G. Seco-Granados, L. Jiménez L, et al. "La Evaluación de Competencias en los Trabajos Fin de Estudios” (in Spanish), IEEE-RITA. Revista Iberoamericana de Tecnologías del Aprendizaje, vol. 5, no. 3, pp. 107114, 2010.

[9] M. Rullan, G. Estapé-Dubreuil, M. Fernández, and M.D. Márquez, "La evaluación de competencias transversales en la materia Trabajo Fin de Grado. Un estudio preliminar sobre la necesidad y oportunidad de establecer medios e instrumentos por ramas de conocimiento," (in Spanish). Revista de Docencia Universitaria, vol. 8, no. 1, pp. 74-100, 2010.

[10] Project reference: Practices towards the excellence of the Bachelors Final Projects. Elaboration of a catalogue of practices based on matching the national and international frameworks and experience in the field of Engineering Education. Analysis of the projection and transfer to other contexts. Studies and Analysis Programme. Grant addressed to project financing for the improvement of higher education quality and university teachers activity in 2011. MICINN (Ministry of science and Innovation). Government of Spain.

[11] D. Hernández-Leo, V. Moreno, and I. Camps, "Teacher's guide to monitoring and assessment for Bachelors Final Projects,” Teaching Quality and Innovation Support Unit, Polytechnic School, Universitat Pompeu Fabra, Barcelona. http://repositori.upf.edu/handle/10230/20036 Accessed $22^{\text {nd }}$ April 2014

[12] R. Voorhees, "Measuring what matters: competency-based learning models”. Higher Education. San Francisco: Jossey Bass, 2001.

[13] M.A. Zazueta and L.F. Herrera, "Rúbrica o matriz de evaluación, herramienta de evaluación formativa y sumativa”, Quaderns digitals, 55, 2008 http://www.quadernsdigitals.net/

[14] J. Mateo, A. Escofet, F. Martínez-Olmo, J. Ventura, and D. Vlachopoulos, "Evaluation Tools in the European Higher Education Area (EHEA): an assessment for evaluating the competences of the Final Year Project in the social sciences," European Journal of Education, vol. 47, no. 3, pp. 435-447, 2012.

[15] D. Escudero and D. Hernández-Leo, "Aplicación de buenas prácticas para la mejora de la calidad de los trabajos de fin de grado en Ingeniería en Diseño Industrial," (in Spanish) Simposio Internacional sobre Innovación y Calidad en la Formación de Ingenieros, Valladolid, Spain, 2012. https://repositori.upf.edu/handle/10230/17047 Accessed: $20^{\text {nd }}$ April 2014

[16] V. Moreno, D. Hernández-Leo, I. Camps, and J. Melero, "Uso de rúbricas para el seguimiento y evaluación de los trabajos de fin de grado," (in Spanish) II Congreso Internacional sobre evaluación por competencias mediante eRúbricas, Málaga, Spain, 2012 http://repositori.upf.edu/handle/10230/19801 Accessed: $8^{\text {th }}$ April 2014

[17] D. Hernández-Leo, V. Moreno Oliver, I. Camps, R. Clarisó, A. Martínez-Monés, M.J. Marco-Galindo, J. Melero, "Implementación de Buenas prácticas en los Trabajos Fin de Grado,” Revista de Docencia Universitaria. REDU. Vol. 11, pp. 269-278, 2013 http://redu.net/redu/index.php/REDU/article/view/652 Accessed 22nd April 2014.

[18] D. Hernández-Leo, and V. Moreno Oliver, "Herramienta Web para el Seguimiento y Evaluación de los Trabajos Fin de Grado,” (in Spanish) III Jornadas de Innovación Educativa en Ingeniería Telemàtica, Granada, Spain, 2013. http://repositori.upf.edu/handle/10230/21028 Accessed $5^{\text {th }}$ April 2014. 